\title{
Chemical Control of Cellular Polarity in Root Hair Formation in Gibasis geniculato
}

\author{
Yutaka Yamazaki \\ Department of Biology, Faculty of Science, \\ Yamagata University, Yamagata, 990 Japan
}

Accepted June 17, 1985

Before formation of the root hair, in Gibasis geniculata (Tahitian bridal veil), the cell of young root epidermis is unequally cloven into two daugaher cells, one is shorter containing full of cytoplasm, and the other is longer containing less cytoplasm. The root hair is primarily formed in the shorter cell which was called trichoblast by Leavitt (1904). Later, the longer cell also gains ability of forming a root hair. In either case, the root hair protrudes ordinarily at an apical part of the cell, and this apico-basal polarity is not altered even by a strong centrifugation which moves intracellular materials as reported formerly (Nakazawa and Yamazaki 1982). On the other hand, it is known that the polar growth of the root hair is maintained by orientation of microtubules in Equisetum (Emos 1982), and there are similar cases also in caulonema of Funaria (Schmiedel and Sehnepf 1980). Such being the case, the cellular polarity in root hair formation will be controlled by some chemical agents. The present report is concerned with this question.

\section{Material and method}

The material is adventitious roots growing out of stem cuttings of Gibasis geniculata. Two to $3 \mathrm{~cm}$ long stem cuttings including 2 nodes were placed horizontally on wet blotting paper in Petri dish, covered, and cultured under diffuse light of laboratory with temperature of 20 to $25^{\circ} \mathrm{C}$. In 2 days, 1 to 3 adventitious roots with root hairs were formed at the nodes of the cutting. These stem cuttings with the vividly growing adventitious roots were cultured dipping the root tip in the following 9 agent solutions: 1) $10^{-4} \mathrm{M}$ colchicine (Nakarai Chem. Co.) dissolved in water, 2) $10^{-5} \mathrm{M}$ cytochalasin B (Sigma) dissolved in $10 \mu \mathrm{g} / \mathrm{ml}$ dimethylsulfoxide water solution, 3) $10^{-3} \mathrm{M}$ mercaptoethanol (Nakarai) dissolved in water, 4) $10^{-4} \mathrm{M}$ morphactin (Merck) dissolved in Knop's medium, 5) $10^{-3} \mathrm{M}$ TIBA (2,3,5-triiodobenzoic acids, Nakarai) dissolved in water, 6) $10^{-4} \mathrm{M}$ kinetin (Nakarai) dissolved in water, 7) $10^{-3} \mathrm{M}$ cysteine (Nihon Rika Chem. Co.) dissolved in water, 8) $10^{-7}$ M IAA (potassium salt of indole-3-acetic acid, Nakarai) dissolved in water, and 9) $10^{-5}$ M CEPA (2-chloroethanephosphoric acid, Sigma) dissolved in water. For the standard culture was used deionized tap water instead of chemical agents. All cultures were carried out in Petri dishes under diffuse light, temperature being 20 to $25^{\circ} \mathrm{C}$. Observation was recorded 2 days after start of the experimental culture. Experiments were repeated at least 3 times. 


\section{Result and discussion}

As a result: 1) young epidermal cells were hypertrophied with colchicine to globular forms, no new root hairs did occur, and the root hairs already formed before application of colchicine grew in irregular patterns (Fig. 1) as in case of Bryopsis branches cultured with colchicine (Nakazawa and Sasaki 1982). Sometimes are seen multiple nuclei in the hypertrophied cell. 2) Cells also lost polarity with cytochalasin $\mathrm{B}$ and one or more root hairs occurred irregularly in different positions of the same cell, and sometimes the root hair was ramified (Fig. 2). In the culture with mere dimethylsulfoxide solution of the same concentration without cytochalasin B, the cellular polarity was usual, forming only one root hiar at the
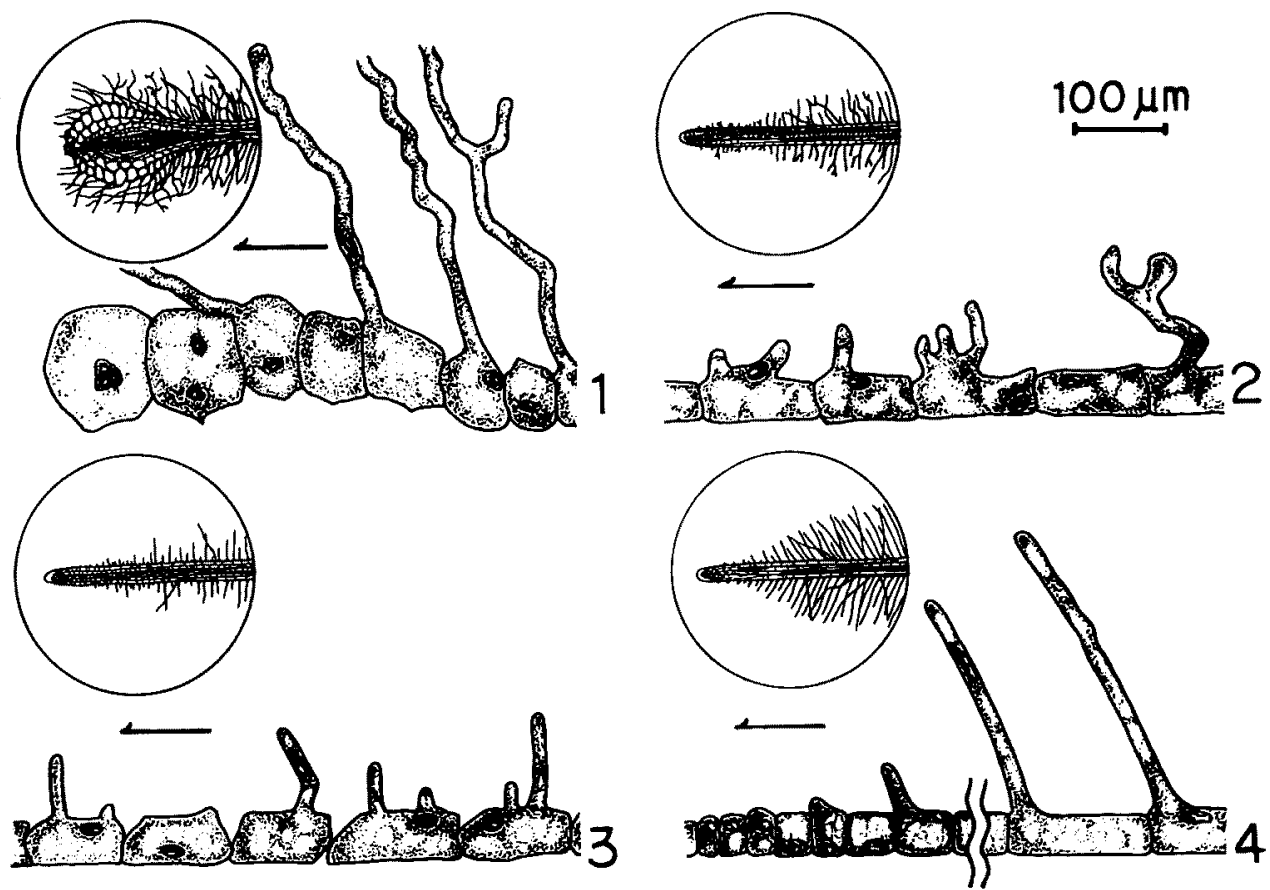

Figs. 1-4. 1, root tip (in circle) and epidermal cells hypertrophied with $10^{-4} \mathrm{M}$ colchicine. 2, root tip (in circle) and epidermal cells forming root hairs abnormally with $10^{-5} \mathrm{M}$ cytochalasin $\mathbf{B}$. 3 , root tip (in circle) and epidermal cells with diminishing polarity in $10^{-4} \mathrm{M}$ morphactin. 4 , standard culture. Arrow indicates direction of root apex.

apical end of the cell. 3) Cellular polarity was not always lost with mercaptoethanol, but sometimes the cell was hypertrophied, and the root hair's polarity was lost in shape of a baloon as in case of fern rhizoids (Nakazawa 1968). 4) Cells lost polarity with morphactin and multiple abnormal root hairs occurred at various positions of the same cell (Fig. 3). 5) Cells lost polarity with TIBA, root hairs formed irrespective of the apico-basal relation of the cell. 6) The cell was not affected by kinetin, but root hairs were hypertrophied in globular forms. 7) Neither cellular polarity nor the form of root hair was influenced by cysteine, but the basal 
part of the cell was extremely elongated to slender forms, as a result, the root hair is situated at the extremely apical end of the long cell. 8) Formation of root hair was inhibited with IAA and the cells were generally hypertrophied. 9) Root hairs were specially elongated with CEPA, the cellular polarity was influenced, but cellular elongation was suppressed so that the root hairs look densely gathered. 10) In the standard culture with deionized tap water, the cellular polarity as well as the polarity of root hairs was usual (Fig. 4).

Discussion of the above results is not always easy. But it is considered that the polarity of root hair-forming cell is maintained by a cortical cytoskeleton as remarked by Barlow (1984). If so, the cytoskeleton must be sustained by two components, the one is microfilaments since the polarity is disturbed by cytochalasin $B$, and the other is microtubles since the polarity is lost with colchicine as in the above experiments. Herein, a microtubule-microfilament system as the cytoskeleton in the cortical cytoplasm must be presumed for stabilizing the cellular polarity. As to the other chemicals, their role for polarity is not always clear, but it seems that the hypertorophy diminishes cellular polarity. Position of the nucleus does not seem to be related to initiation and further growth of the root hair as seen in Figs. 1 to 4 .

\section{Summary}

Young adventitious roots of Gibasis geniculata were cultured with some chemical agents dissolved in water to examine the cellular polarity with respect to root hair formation. As a result, $10^{-4} \mathrm{M}$ colchicine, $10^{-5} \mathrm{M}$ cytochalasin $\mathrm{B}, 10^{-4} \mathrm{M}$ morphactin, and $10^{-3} \mathrm{M}$ TIBA were specially effective for disturbing polarity.

\section{Acknowledgements}

The author expresses his cordial thanks to Prof. Singo Nakazawa for the experimental guidance. Thanks are also due to the late Prof. Fumio Maekawa for identification of the material.

\section{References}

Barlow, P. W. 1984. Positional controls in root development. In Positional Controls in Plant Development, ed. Barlow, P. W. and Carr, D. J., Cambridge Univ. Press, pp. 281-318.

Emos, A. M. C. 1982 . Microtubules do not control microfibril orientation in a helicoidal cell wall. Protoplasma 113, 85-87..

Laevitt, R. G. 1904. Trichomes of the root in vascular cryptogams and angiosperms. Proc. Boston Soc. Nat. Hist. 31 : 273-313.

Nakazawa, S. 1968. Growth patterns of fern gametophytes with colchicine and sulfhydril groups. Bot. Mag. Tokyo 81 : 575-581.

- and Sasaki, R. 1982. Polarity disturbance in regeneration of Bryopsis by colchicine. Bull. Yamagata Univ., Nat. Sci. 10: 313-317.

- and Yamazaki, Y. 1982. Cellular polarity in root epidermis of Gibasis geniculata. Naturwissenschaften 69: 396.

Schmiedel, G. and Schnepf, E. 1980. Polarity and growth of caulonema tip cells of the moss, Funaria hygrometrica. Planta 147: 405-413. 